\title{
REFLEXIONES EN TORNO A HEIDEGGER Y EL NACIONALSOCIALISMO
}

\author{
Eduardo Carrasco P. \\ Universidad de Chile \\ educarr@manquehue.net
}

\begin{abstract}
Resumen
El artículo busca discutir algunos de los posicionamientos de Heidegger en su época nazi, mostrando que la base de su error político está en su nacionalismo. Esto lo ha hecho caer en una interpretación de la historia de Alemania como una opción opuesta a la modernidad y lo ha inducido a perder de vista las relaciones de interdependencia mutua entre facticidad y trascendencia. El nacionalismo se presenta así como un desvío del propósito universalista de la filosofía y el error de Heidegger como un abandono del propósito esencial de la filosofía.
\end{abstract}

PALABRAS CLAVE: Heidegger, nacionalismo, nacionalsocialismo, modernidad.

\section{Abstract}

We discuss some aspects of Heidegger's stance during his nazi period. We show that the root of his political error lies in his nationalism. This led him to understand the history of Germany as an option opposed to modernity, while losing sight of the mutual dependence of facticity and transcendence. Nationalism appears thus as a deviation from the universalist aim of philosophy and Heidegger's error as defection from philosophy's essential purpose.

KEYWORDS: Heidegger, nacionalism, nacionalsocialism, modernity.

\footnotetext{
$\overline{\mathrm{RA}}$ La publicación de escritos de Heidegger procedentes de la época en que se alineó con el nacionalsocialismo permite aclarar en algunos aspectos el carácter de su interés por esta ideología. La alocución de Heidegger pronunciada el 17 de mayo de 1933, inmediatamente después de haber escuchado el discurso de Hitler en un estadio universitario y en el que este último aseguraba que Alemania renunciaba a la guerra como solución de los problemas de Europa y pedía el desarme de las potencias occidentales, resume la idea básica que pone de manifiesto la forma de su compromiso con el nazismo. Esta es la de "resolución" (Entschlossenheit), la voluntad firme y decidida. "Resolución" significa que frente a los acontecimientos políticos de la época, que en cierta manera ya han decidido las cosas a favor del nazismo, hay que comprometerse a fondo con el movimiento e intentar darle una dirección positiva. La
} 
idea incluye a su vez los conceptos de "disponibilidad" (Bereitschaft) y de "camaradería" (Kameradschaft): "la disponibilidad de ir hasta el fin de lo posible y la camaradería hasta el último extremo" (GA16 p. 104). Como veremos, por su voluntarismo y extremismo, ambas corresponden exactamente a un rasgo característico del espíritu nazi y que Heidegger aquí asume en plenitud y sostiene públicamente. Al mismo tiempo, por la misma razón, ambas son absolutamente contrarias al espíritu de la filosofía. En beneficio de Heidegger puede decirse que su alocución está hecha con el propósito de apoyar un discurso sobre la paz, que en ese momento fue saludado con entusiasmo y buena fe por muchos alemanes. Lamentablemente, este pacifismo no era otra cosa que una máscara de las verdaderas intenciones belicistas de Hitler, las que más adelante se mostrarían con toda claridad. En todo caso, lo más grave aquí es el militantismo irreflexivo que expresan las ideas de esta alocución.

La primera de estas ideas, la "disponibilidad", se refiere a la decisión de ponerse al servicio del Estado y de sus dictámenes, a la resolución de llegar hasta las últimas consecuencias cuando se trata de "tomar el camino difícil de nuestra historia, el que es exigido por el honor de la nación y la grandeza de nuestro pueblo" (GA16 p. 104). Como se ve, se trata de afirmar una voluntad de llegar hasta el fin, de una decisión extremista que se ubica desde un comienzo en el terreno de los afectos patrióticos y políticos y que, en cuanto tal, no está dispuesta a guardar ni la menor distancia en el apoyo resuelto a las decisiones del Führer. "Nos hemos decidido", afirma Heidegger con convicción, como si todo un asunto complejo como es el de cualquier definición de política interior o exterior se expresara cabalmente a través de una decisión voluntaria, como si el problema de donde esté el honor de una nación y la grandeza de un pueblo estuvieran perfectamente resueltos por una consigna partidista y solo bastara con seguir el camino trazado por el líder. Además, hay aquí un carácter extremo que se significa con la voluntad de estar dispuesto a todo en la decisión que se ha tomado, lo que transforma a esta última en una cuestión de vida o muerte. Esta ubicación de las decisiones en el terreno puramente afectivo es lo propio de la actitud militante y su forma fanática y extremista, que es la que aquí aparece, lo propio del militante nacionalsocialista. Veremos de qué manera se entrelaza esta actitud con la segunda idea expresada aquí, la de "camaradería".

En las dos conferencias para los cursos extranjeros pronunciadas en la Universidad de Friburgo el 15 y el 16 de agosto de 1934, esto es, tres meses después de su renuncia a la rectoría y publicadas en el tomo XVI de la Gesamtausgabe, se aclara perfectamente lo que Heidegger entiende por este concepto. En estas conferencias, el pensador entrega su interpretación del nacionalsocialismo y su valoración de la importancia de la revolución que este movimiento está llevando a cabo. Su explicación vuelve a exponer ideas que muchos otros analistas ya habían mostrado y que hoy día han sido también recogidas en diferentes estudios sobre el fenómeno. Se trata de lo que el escritor italiano Doménico Losurdo (CMO) ha denominado la "ideología de la guerra" y que él ha mostrado como un fenómeno no exclusivamente alemán, sino presente en muchos otros países europeos en la misma época de postguerra. Esta idea, que tiene importantes representantes como Benedetto Croce, Max Weber, Simmel, Scheler, Spengler y Jünger, sin necesidad de glorificar la guerra, reivindica el espíritu 
de comunidad orgánica surgido en el frente, como respuesta a la decadencia de la disciplina social propia de las sociedades de postguerra. En el texto citado, Heidegger afirma esto mismo sin ambigüedades: "La verdadera preparación para la Revolución Nacionalsocialista comenzó de inmediato, inconscientemente, en la Primera Guerra Mundial y, ciertamente, durante ésta. En el Frente (de batalla) se realizó una experiencia totalmente nueva. Allí se creó una idea totalmente nueva de comunidad (Gemeinschaft). Este espíritu nuevo del Frente portaba en sí mismo la fuerte voluntad de hacerse realmente efectivo después de la guerra como fuerza determinante en la existencia del pueblo" (GA16 pp. 298-299).

Este tipo de nueva comunidad, que el nacionalsocialismo ha sabido expandir hacia la sociedad en su conjunto a partir de la experiencia del Frente, es lo que Heidegger llama "camaradería". La define con la exactitud y el rigor acostumbrados en todos sus escritos: La camaradería "es un tipo de pertenencia recíproca, en la que cualquiera se pone en forma incondicional para con el otro, en cualquier situación. La camaradería es un aprontamiento semejante. ¿Y donde encuentra su fundamento? En que cada uno reconoce en cualquier otro los mismos desafíos, resiste idéntico apremio, corre el mismo peligro, es decir, sigue la misma tarea sirviendo" (GA16 p. 299). En cuanto forma de relación que brota de la sociabilidad militar, la camaradería está en estrecha relación con el ideal prusiano que busca transformar los vínculos de ciudadanía en lazos tan firmes y disciplinados como los que existen entre militares.

Que el ideal de comunidad pueda corresponder a la cohesión de mutua dependencia existente entre los soldados en el frente de batalla es algo altamente discutible, en cuanto con ello es la organización militar la que se hace valer como ideal de sociabilidad. Es cierto que desde el peligro de muerte al que todos los soldados están expuestos se genera un espíritu de grupo muy intenso, en el cual se experimenta constantemente la mutua pertenencia y la correlativa dependencia. Este tipo de cohesión obliga a los que forman parte del grupo a respetar al máximo las jerarquías existentes dentro de él y a que cada cual ordene su acción en función del objetivo común. Se trata de una forma límite de sujeción del individuo al colectivo al que pertenece; por eso, en este tipo de agrupaciones el funcionamiento de cada componente implica necesariamente una subordinación a las instancias ordenadoras del grupo. Las jerarquías son respetadas en un sentido extremo y cada cual pone su individualidad al servicio del interés común, que es el de lograr la meta bélica fijada, salvando a la vez la propia vida. Pero este tipo de sujeción al grupo lleva implícita la anulación de la individualidad y la obediencia sin discusión al que manda, lo cual requiere, entre otras cosas, poner entre paréntesis el propio pensamiento o el sentido crítico, en orden a cumplir los objetivos planteados, que son precisamente los que configuran al grupo como tal. En la formación de un soldado es fundamental el aprendizaje de la obediencia, que se entiende como el cumplimiento estricto de las órdenes que dan los jefes, y esto, sin réplica ninguna, pues de existir alguna, ello se traduciría en una interrupción de la acción que se está acometiendo, con consecuencias que podrían ser desastrosas para todos. El paso a la acción, aunque esto fuera momentáneamente, suprime la reflexión y obliga a cada uno de los componentes del grupo a poner toda su voluntad en el cumplimiento de la orden dada. Por eso se habla de "obediencia ciega". Sin esta 
condición, ninguna operación puede ser llevada a cabo. La militarización es, entonces, necesariamente la subordinación y la obediencia a la autoridad. Mandar y obedecer son las formas en que opera este tipo de organización, la cual, por eso mismo, alcanza la máxima eficacia posible dentro de las limitaciones de quienes forman parte de ella.

"La camaradería como forma fundamental de comunidad surge primeramente de los que se ven conducidos al servicio de la misma obligación", dice Heidegger (GA16 p. 299). Es cierto que la obligación puede a su vez tener su fundamento en lo que cada cual decide por sí mismo hacer o no hacer. Pero es un hecho que esta forma libre del asentimiento a una obligación no existe en la guerra. En ella, los soldados se ven obligados a enrolarse y a ir al frente, y esto, a riesgo de su propia vida. Se trata de una situación límite, en la cual, si no se desea ser encarcelado y hasta fusilado en caso de deserción, esto es, si no se desea perder la vida, el honor o la dignidad, uno está obligado a enrolarse. Por tanto, se trata más bien de una limitación social de la libertad en la que el individuo queda obligado en forma absoluta a asumir una situación en la que de hecho se ha suprimido su posibilidad de elegir. Es la imposición del lazo de pertenencia por encima de la individualidad, y ese es el motivo por el cual esta situación puede aparecer equivocadamente como ideal de lo social. En realidad, en estos casos el poder social es tan grande que simplemente aplasta toda posible elección individual, la cual, frente a lo que aparece como el interés común, pierde toda legitimidad. Erigir este caso en un ejemplo de sociabilidad es transformar la necesidad en virtud y anular la única posible y verdadera sociabilidad que no nace de la obligación, sino de la libertad, cuyos ejemplos podrían encontrarse en otras formas de compañerismo, en la amistad, en el amor, en los lazos familiares o en la condición natural de todo ser humano de llegar al mundo en medio de una situación ya decidida y en la que ya habitan otros seres semejantes a él. El aplastamiento de la individualidad en aras de lo común cohesiona de un modo casi perfecto al grupo, pero a la vez, transforma la adhesión de los integrantes de este en obligación y no en decisión libre.

Pero, es cierto que vistas las cosas desde el punto de vista del Estado, la experiencia de las relaciones militares pareciera la forma ideal de sociabilidad, puesto que en ella el individuo se transforma en un factor que pone toda su fuerza en el objetivo que aquél se proponga y anula todo posible roce que dificulte ese logro. Solo que de esta manera es el individuo el que queda sometido en forma absoluta a la obediencia. De ahí que en el texto de Heidegger aparezcan de manera tan insistente las ideas de obligación y de obediencia. Este lazo de sociabilidad obligada no es más que una forma extrema de la sociabilidad directa que corresponde a la situación en que está cada ser humano por el hecho de haber venido al mundo en un lugar determinado. Esta sociabilidad espontánea y, por así decirlo, "natural", no es vivida como una obligación, sino más bien como una circunstancia en la que se está, la cual, además, es contingente, pues el lazo de pertenencia que se descubre a partir de ella podría ser cualquier otro. Es de mala fe pensar que la pertenencia de cada ser humano a una nación es un hecho necesario y, por tanto, obligatorio. La obligación que caracteriza el vínculo de los soldados en la guerra está dada por la situación precisa de peligro que los afecta a todos por igual y los hace interdependientes. Pero, es muy diferente la 
condición de pertenencia en la cual cada uno se encuentra sin haberla decidido, y debida al hecho azaroso de haber nacido en ese determinado país. Esta sociabilidad "natural" que, por lo demás, como ya lo hemos dicho, es idéntica en todos los hombres, es la única verdadera base de la sociabilidad política. Lo cual obliga a considerar esta universalidad como el único verdadero fundamento de toda reflexión sobre la política, y a todo nacionalismo extremo como una forma de escabullirse de esta verdadera condición. El nacionalismo del nacionalsocialismo y, por lo tanto, el de Heidegger, es una negación de la condición de universalidad que caracteriza la esencia de lo humano y una interpretación equivocada del vínculo político.

Es fácil darse cuenta de que este tipo de sociabilidad guerrera es completamente ajena a la filosofía, que exige necesariamente lo contrario, esto es, la afirmación que hace el pensamiento de su propio derecho y de su propia libertad. Heidegger parece haber olvidado aquí la diferencia que tan minuciosamente ha establecido Platón entre las figuras del filósofo y la del militar en la Politeia, que en lo esencial se mantiene todavía perfectamente válida. Filosofía es un tipo de no subordinación, y más todavía cuando se trata de bajar la cabeza ante un poder que no es el del propio pensamiento. Por eso, la filosofía solo es posible en la medida en que todavía no se pase a la acción, pues cuando esta decisión llega, todo pensamiento se hace improcedente o inútil. Pero no solamente los filósofos tendrían que rechazar esta forma de constituirse la sociedad, sino todo individuo que busque afirmar sus derechos individuales y su libertad de pensamiento y acción. Cuando Heidegger, en la línea del nacionalsocialismo, afirma este ideal de sociedad fundado en la organización militar, está lisa y llanamente volviendo atrás en la evolución histórica de las libertades, y buscando un régimen que nada tiene que ver con los ideales de un filósofo. No es una casualidad que en los escritos de esta época, Heidegger utilice a menudo la palabra "servicio" (Dienst), lo que muestra que en su pensamiento político siempre ha estado presente este principio de subordinación que interfiere gravemente con los propósitos del pensamiento. La ciudadanía no puede constituirse a partir de un "servicio", porque eso significa que se asume la sociabilidad como una forma de esclavitud y no como un medio para alcanzar la expansión de la propia libertad y la autonomía. Pero, además, pensar la sociabilidad de esta manera presupone haber hecho ya una decisión con respecto al carácter nacional del vínculo político, con la ya aludida negación de la universalidad que está en la base de toda sociabilidad humana. La universalidad no es solamente el territorio donde crece y se desarrolla la filosofía, sino también el fundamento de toda sociabilidad. Por supuesto que se puede ser alemán, chileno o finlandés, pero eso no significa que por ello se deje de ser hombre. Nuestras pertenencias se interrelacionan unas con otras, sin que necesariamente se excluyan, y cuando esto ocurre, como es el caso en el nacionalismo ultrancista nazi, se cae de inmediato en la negación de la esencialidad humana, anulándose o relativizándose con ello lo que tengo en común con todos los demás seres humanos.

Es en su discurso del rectorado donde Heidegger más claramente expresa este concepto limitativo de lo social. Allí habla en efecto de un "servicio de trabajo" (Arbeitsdienst), de un "servicio militar" (Wehrdienst) y de un "servicio del saber" (Wissensdienst) a los que los estudiantes universitarios deberían obligarse. Se trata 
del deber que los jóvenes tienen con su pueblo y que debe expresarse en su dedicación al trabajo, del deber ante el destino de la nación en medio de otros pueblos, que debe expresarse en la disponibilidad para el enrolamiento, si ello se hace necesario, y del deber ante la "misión espiritual del pueblo alemán", que debe manifestarse en la dedicación al saber "más alto, más vasto y más rico". Y, sin embargo, es el propio Heidegger quien ha mostrado en textos posteriores a este, de qué modo la filosofía responde a una vocación libertaria y por eso no puede servir a nadie ni tampoco servir para nada. El servicio está fuera del dominio del cuestionamiento filosófico, porque este último "es enteramente libre y voluntario, establecido plena y expresamente sobre una base secreta de libertad, sobre lo que nosotros hemos llamado el salto. Nietzsche dice todavía: "la filosofía... es la vida libre y voluntaria en los hielos de las altas montañas” (XV,2). Así, nosotros podemos ahora decirlo, filosofar es un cuestionar extraordinario, fuera del orden (ausserordentlich) sobre lo que está fuera del orden (das Ausserordentliche) (IA, p. 25).

Lo curioso es que este texto provenga de un curso dictado en 1935, fecha en la cual se puede suponer que Heidegger todavía mantiene su compromiso con el nazismo. De acuerdo con el testimonio de Kart Löwith (LD) en el que relata su último encuentro con Heidegger en abril de 1936 en Roma, todavía en esa fecha Heidegger mantenía su convicción de que "el nacionalsocialismo era el camino al que Alemania estaba predestinada y que solo se trataba de perseverar". Puede afirmarse que solo a partir de 1936 Heidegger comienza a apartarse del nazismo y esa fecha coincide también con el hecho de que sus escritos y cursos universitarios comiencen a ser vistos con sospecha por los organismos de seguridad del Estado nazi. Si bien no poseemos datos biográfios suficientes que nos permitan fechar precisamente su alejamiento del nazismo, en el dominio del pensamiento puede establecerse que los seminarios y escritos sobre Nietzsche marcan su confrontación pensante con esta ideología: los seminarios han tenido lugar entre 1936 y 1940; los escritos, que han sido publicados en 1961 en los dos tomos del libro Nietzsche se ubican entre los años 1936 y 1946. En ellos se parte haciendo una exposición del pensamiento de Nietzsche muy apegada a sus textos, para terminar entregando una interpretación original del fenómeno del nihilismo y de la técnica. Por lo tanto, vemos que en el periodo de su adscripción al nazismo, Heidegger se ha desviado claramente de los propósitos universalistas y libertarios de la filosofía, pero por otra parte, también tenemos que afirmar que esta desviación comienza a corregirse parcialmente a partir de 1936. La edición de su libro sobre Nietzsche fue ingenuamente programada para que en parte se entendiera como una respuesta a los cuestionamientos políticos que se le hicieron con posterioridad a su experiencia del rectorado. Y efectivamente su interpretación de Nietzsche no solamente se aleja de las lecturas nacionalsocialistas de Bäumler y Rosenberg, sino que además ubica al nihilismo, donde claramente se incluye el nazismo, en las antípodas de su nuevo pensamiento. Pero esta orientación quedó muy alejada de las posibilidades de comprensión de la opinión pública y ni siquiera hoy día, a casi 50 años de su publicación, esta obra ha sido suficientemente apreciada en tanto reorientación de su pensamiento sobre el nazismo. 
Prueba de este distanciamiento con respecto a este movimiento son las palabras finales del curso sobre Nietzsche, anunciado por Heidegger para el semestre de invierno de 1941-1942, pero que finalmente no fue dictado. De acuerdo con los datos que nos entrega el mismo pensador, este curso titulado "La metafísica de Nietzsche" fue escrito en el mes de agosto de 1940 y retocado en septiembre del mismo año. Las palabras finales de este curso son las siguientes: "Lo que se dice en el pensamiento de los pensadores europeos puede históricamente ser puesto a cuenta de su identidad nacional, pero no puede ser jamás presentado como una particularidad nacional. El pensamiento de Descartes, la metafisica de Leibniz, la filosofía de Hume son cada vez europeas y por esta razón han llegado a ser planetarias. De la misma manera, en lo que es esencial, la metafisica de Nietzsche no es de ninguna manera una filosofía específicamente alemana. Ella es europea planetaria. Los alemanes no hacen más que ir laboriosamente a la zaga detrás de esta metafísica. El imperio británico se ha alzado desde hace ya largo tiempo a su nivel, concretando cada uno de sus estadios esenciales" (GA50 pp. 81-82). Esto muestra que a estas alturas, Heidegger ya se ha ubicado bastante lejos de sus devaneos políticos hitlerianos.

Lo importante de este texto citado es su clara referencia a los países en guerra y su interpretación crítica respecto de Alemania. De acuerdo con sus palabras, el imperio británico puede presentarse con mayor legitimidad como heredero de Nietzsche que los propios alemanes, que no hacen otra cosa que intentar ponerse a la altura de su pensamiento sin conseguirlo. La fuerza de la filosofía occidental europea, que ya no aparece más como un logro nacional, radica en su poder de expansión planetaria. Esta expansión no se debe a que ella sea la que con mayor potencia se desplaza hacia las conciencias de los hombres de la época, sino al modo como ella se "realiza" a través de la técnica y la ciencia, haciendo efectiva la universalidad contenida en su esencia. De esta manera, la historia europea se muestra ahora como el elemento común en el que están teniendo lugar todos los acontecimientos de la historia contingente. La civilización europea tiene una raíz común, que es Grecia, y esto significa, la filosofía. La historia europea es "filosófica" en la medida en que ella es la expansión de la potencia dominante del saber, a partir del cual se explican todos los sucesos que pertenecen a ella. Así, la interpretación de la esencia griega de occidente se mantiene, pero lo que en el Discurso de rectorado aparecía como una misión particularmente "alemana" se muestra ahora como un destino común a todos los pueblos europeos. Quizás lo más significativo de este texto sea el lugar acordado a Inglaterra en esta realización histórica, lo cual no solo significa una revisión radical de lo que afirmaba Heidegger en su período nazi - quien, como todo alemán medianamente informado, preveía ya el resultado final de la guerra en favor de los aliados- sino, además, una revalorización de aspectos de la herencia griega que no habían sido reconocidos con lucidez hasta este momento.

La prolongación de la herencia griega no está dada solamente por la fuerza que adquiera el pensamiento filosófico en un determinado país, sino -en la medida en que el carácter "fillosófico" del destino occidental no se juega solamente en el modo como se cultive la filosofía, sino en múltiples otros factores que señalan su presencia- en la fuerza expansiva de dominación política, económica y cultural que confirme esta 
misma herencia. De este modo, el Imperio Británico ha sido mucho más eficaz que Alemania en la empresa de asentamiento del dominio occidental en el mundo moderno, cumpliendo de este modo de mejor manera la idea de la voluntad de poder contenida en la metafísica de Nietzsche. En ese sentido puede afirmarse que los ingleses han sido más dignos herederos de la filosofía de Nietzsche que los propios alemanes, que no hacen otra cosa que intentar sin grandes éxitos llevar a cabo esta empresa. Es importante, sin embargo, no entender estas ideas dentro de los esquemas más difundidos de expansión imperialista o de empresa política de occidentalización del mundo. En realidad, de lo que se trata aquí es de mostrar el movimiento real de la historia, no de afirmar cuestiones de principio que posteriormente servirían para legitimar tales movimientos. De lo que se trata es de dar cuenta de lo que está teniendo lugar en la historia y de acercarse a una comprensión de ello. Independientemente de los designios políticos que puedan haber tenido los protagonistas de la historia occidental, esta ha seguido una dirección innegable que Heidegger intenta detectar: esta es la planetarización de lo europeo a través del dominio técnico y científico fundado en la raíz filosófica. Esta situación ha llegado a ser así por las tendencias dominantes a las que se han visto sometidos los hombres en su actuar histórico: por eso es necesario comprender que la historia es "destinal" y no producto de una planificación humana. Lo cual nada tiene que ver con la atribución de responsabilidades que puedan o no determinarse frente a hechos concretos. Solo tiene sentido determinar responsabilidades en un nivel personal o individual; en todos los demás ámbitos más generales los pueblos o las instituciones hacen lo que pueden y son arrastrados por corrientes que en verdad ninguna voluntad humana podría contrariar. Nadie es responsable del paso de una época a otra, de una crisis financiera que afecta a un continente, de un cambio de tendencia en la moda mundial, en la música o en la política. Todas estas cosas suceden como un inmenso océano de constantes oleajes que van en diferentes direcciones, y los hombres navegan o naufragan en medio de ellas sin grandes posibilidades de orientar definitivamente su rumbo.

Es claro que en estas consideraciones sobre el nazismo que se encuentran en las conferencias dictadas en la Universidad de Friburgo, Heidegger está hablando desde una determinada concepción del Estado y desde una especial idea de las relaciones entre individuo y Estado. Esta idea nace de una crítica a la forma de modernidad política que, según él, ha caracterizado el desarrollo histórico de Europa desde la Revolución Francesa en adelante. El pensador establece tres características de lo que habría sido este proceso de emancipación (Befreiung):

1. El desligarse del régimen de vida sobrenatural de la iglesia cristiana y de la autoridad de los dogmas. El hombre traslada su acción y su saber a las energías propias del cálculo del mundo, de la invención, del descubrimiento y de la conquista de tierras extrañas y territorios por el globo. 
2. El desligarse del hombre de sus lazos con las criaturas naturales, con los seres vivos y lo orgánico. Conversión de toda la naturaleza a lo mecánico calculable, a lo que es controlable según las máquinas.

3. El desligarse del hombre fuera de su comunidad y de las regulaciones originarias. El hombre que se sabe a sí mismo (algo) individual, es el elemento normativo y el fundamento configurador de la nueva regulación. La comunidad se hace ahora una sociedad, es decir, una asociación de muchos individuos, en virtud de su compromiso y su contrato de acuerdo a una racionalidad. El Estado se halla fundado sobre un contrato (GA16 p. 290).

Para todo el que haya leído a Heidegger queda inmediatamente claro que en esta caracterización de la modernidad hay un fondo crítico. Lo que está en juego aquí es una determinada manera de comprender esta época, pero desolidarizándose, por decirlo así, de la continuidad del proceso. En general, cuando se habla de temas de Historia Universal o de Historia Europea se acostumbra ver estos procesos en una línea continua de evolución en la que todos los pueblos participan por igual con sus experiencias históricas particulares. En la resolución del conflicto entre razón y fe, en el terreno del saber que ha tenido lugar durante el Iluminismo, por ejemplo, y al que alude la primera característica anotada por Heidegger, han participado todos los grandes pensadores europeos sin excepción, y es precisamente esta unidad en la dirección lo que permite hablar de una "historia europea". El célebre libro de Cassirer sobre la ilustración ( $\mathrm{PhA})$ es un buen ejemplo de descripción de una época en la cual la pertenencia nacional de los diferentes pensadores considerados no deja de ser una mera anécdota. No se ve que existan dos o más posibles caminos históricos paralelos, pues la época atraviesa los países sin que las particularidades nacionales jueguen ningún rol demasiado importante. En la exposición de Heidegger, sin embargo, se presentan las cosas de un modo diferente, como si Alemania fuera un país aparte, que hubiera vivido la modernidad como a contrapelo y en el que este proceso más bien hubiera ocultado su verdadera esencialidad. Hay algo de mala fe en esto, pues se trata de separar lo que efectivamente ha ocurrido en la historia, de lo que, de acuerdo con una cierta idea idealizada que se tiene del país, debería haber sido. Por eso aparece señalada esta dicotomía, que sería bastante difícil de admitir sin hacerse cargo del prejuicio que le atribuye al país una esencia pura y limpia que las dificultades históricas o las voluntades de otros pueblos han impedido que se muestre a la luz. Esto se parece mucho a la idea nazi según la cual lo alemán estaría intervenido por fuerzas extrañas que cohabitarían en su seno y que se trataría ahora de eliminar para que esta esencia manifestara su pureza. En este "esencialismo" que busca distanciar la historia alemana del proceso de modernidad vemos entonces un nuevo vínculo entre Heidegger y el nazismo. Veamos esto más de cerca, porque en ello se pone de manifiesto algo de suma importancia, la comprensión nacionalista de la historia alemana que está en la base de la adscripción de Heidegger al nacionalsocialismo.

El desligarse de la fe, para entrar en el dominio de la razón afirmándose a sí misma, se interpreta entonces como el comienzo de un antropomorfismo y de un exagerado centralismo del hombre, que ahora intenta, hasta donde le sea posible, 
planificar su existencia en el mundo y controlar las fuerzas de la naturaleza gracias a la técnica y a la ciencia. Esta idea, que posteriormente tendrá una enorme importancia en la interpretación de Heidegger sobre la técnica (Carta sobre el humanismo) no debe confundirse con su posterior formulación. Aquí, lo que se denuncia es un exceso humano, y en este sentido puede decirse que esta primera formulación de la idea cae en el mismo antropocentrismo que ella intenta denunciar. El Heidegger que adhiere al nazismo interpreta estos fenómenos epocales desde un punto de vista nacional, lo cual no es más que un subjetivismo de un pueblo determinado frente a otros subjetivismos diferentes. Pero este pensamiento nacionalista quedará superado cuando las épocas se piensen como modalidades de la historia del ser. Por lo tanto, si bien algunos aspectos de este análisis de la modernidad se mantienen con posterioridad a la guerra, puede afirmarse que la perspectiva que se adopta posteriormente recupera la universalidad que en el periodo nazi se había perdido. Hacer esta diferencia es esencial para no emitir juicios demasiado generales sobre este tipo de caracterizaciones. El abandono del nacionalismo está claramente expresado por Heidegger en la entrevista a Der Spiegel cuando, hablando de su discurso de rectorado, él afirma: "Pero yo retomaría hoy día, todavía más decididamente que nunca esta formulación: "La fidelidad consigo misma de la universidad alemana" sin embargo, sin referencia al nacionalismo" (EP pp. 246-247). Esto significa que él asume que el nacionalismo fue efectivamente un factor que contaminó su pensamiento, y que lo esencial de este último puede ser nuevamente rescatado si extirpamos de él lo que haya de esta desviación. Esta tarea fue efectivamente llevada a cabo por Heidegger, como lo muestra perfectamente la cita aludida de su curso sobre la metafísica de Nietzsche.

Lo curioso es que en todo este periodo de nacionalismo, Heidegger haya permanecido ciego frente al hecho de que estos signos de modernidad que él interpreta como negativos, también eran perfectamente válidos para la interpretación del nazismo. De hecho, muchos especialistas en el tema han sido capaces de mostrar que el nazismo, lejos de ser una alternativa diferente frente a los aspectos excesivos de la modernidad, es su exageración llevada hasta la caricatura. Por de pronto, el estatismo nacionalsocialista no es otra cosa que un intento de planificar y ordenar lo social y económico hasta extremos que, con excepción de los países posteriormente llamados "socialistas", ningún otro país occidental llegó a atreverse a emprender en la misma época. La propia empresa de expulsión y exterminación de los judíos se llevó a cabo como una monstruosa empresa planificada, en la cual los detalles más macabros también entraban en el cálculo técnico. Lo mismo ocurrió con la guerra misma, incluyendo todos sus aspectos, proceso que Jünger ya había definido como "movilización total". De modo que no viene al caso, como quiere Heidegger, poner a Alemania fuera del proceso en que entraron todos los demás países europeos desde el siglo XVII e incluso antes.

Pero, volviendo al texto que analizábamos, como decíamos hace un momento, Heidegger pareciera pensar que Alemania se habría visto arrastrada hacia la modernidad por un movimiento que se oponía a su destino espiritual y que recién aparecería con toda su fuerza a partir del nazismo. La crisis espiritual alemana, visible también en la situación de las universidades, escondería una "Alemania secreta", esencial, que 
poco a poco habría ido mostrándose a través de la poesía (Klopstock, Herder, Goethe, Schiller y el romanticismo), de la filosofía (Kant, Fichte, Schleiermacher, Schelling y Hegel) y de la "nueva voluntad política de los señores y los soldados del Estado prusiano" (Freiherr von Stein, Hardenberg, Humboldt, Scharnhorst, Gneisenau y von Clausewitz). El nazismo sería la manifestación final de este espíritu en el que se encarnaría definitivamente la vocación histórica del pueblo alemán. En lo que se refiere a la relación del hombre con la naturaleza, en lugar de la afirmación unilateral de lo humano frente a un mundo físico entendido como organización maquinal susceptible de poder ser técnicamente dominada, propia del racionalismo francés y del pragmatismo inglés, habría surgido un pensamiento unitario que habría buscado pensar a hombre y naturaleza en su unidad.

De esto surge la segunda característica de la modernidad señalada, que puede aclararnos en qué sentido la biopolítica del nazismo pudo haber sido interpretada como algo positivo por Heidegger. Si bien es difícil aceptar que en él haya habido un antisemitismo biológico, tiene que haber tenido algún tipo de razón para no haberlo rechazado categóricamente como se hubiera esperado de un intelectual como él. La tradición judaica, como lo entendió bien Nietzsche $-\mathrm{y}$ posteriormente, aunque con muy diferentes conclusiones, Levinas- lleva consigo la afirmación de la dualidad entre lo material y lo espiritual; "el cristianismo es un platonismo para el pueblo", dice Nietzsche. De ahí que a Heidegger pueda parecerle que frente al espíritu de unidad que caracterizaría según él a la cultura alemana, el judaísmo sería una línea de desarrollo diferente y en cierto modo opuesto. El fondo de su "antisemitismo cultural" podría estar de esta manera justificado por su aversión a la modernidad, cuya tendencia esencial sería una forma de prolongación del judaísmo y del platonismo. Descartes, confirmando la posición autónoma del hombre ante el resto de la naturaleza, también se presentaría como una confirmación de esta línea de pensamiento. El filósofo francés llevó su idea racionalista del orden universal hasta el extremo de pensar que los animales no eran más que máquinas. Esto significaba otorgarle un dudoso privilegio al ser humano, que por un lado aparecía como un ser único en el universo, pero por otro se pensaba como desligado del resto de la naturaleza. Es este aislamiento el que denuncia Heidegger: "conversión de toda la naturaleza a lo mecánico calculable, a lo que es controlable según las máquinas".

Es cierto que en el idealismo alemán hay una especial dirección de pensamiento en el sentido de la afirmación de la identidad entre hombre y naturaleza, de la inclusión del hombre en la naturaleza y no de la oposición entre ambos que pareciera encontrarse en el proyecto de dominio que caracteriza la modernidad. La filosofía de Schelling tiene este propósito en todas sus numerosas y diferentes formulaciones sistemáticas. Lo mismo ocurre con la poesía de Hölderlin, para el cual la naturaleza es finalmente la entidad en la que toda vida, y no solamente la del hombre, se reabsorbe. Pero no es justo afirmar que esta dirección de pensamiento sea específicamente alemana. De hecho, los propios intelectuales alemanes de esa época han mostrado con gratitud su deuda en este punto con Giordano Bruno, con Spinoza y con Rousseau, quienes son sospechosamente ignorados por Heidegger a través de toda su obra. Lo interesante es que con esta interpretación forzada de la modernidad, Heidegger repite 
un rasgo característico del nazismo, como es el de interpretar lo propio como lo válido y lo bueno, frente a lo del otro, expuesto como malo o deficiente: Alemania tiene un fondo superior al de cualquier otro pueblo, en esa "Alemania secreta" se anida la superación de los errores históricos de la modernidad cartesiana que ahora el nazismo hará surgir. Es como un complejo de "fortaleza asediada" que no sabe afirmar sus propios valores sin buscarse adversarios. Como si se estuviera respondiendo a una desvalorización de Alemania y esta situación obligara a sus defensores a posiciones abanderizadas. Es cierto que a Heidegger le tocó vivir la postguerra en la cual Alemania se encontraba efectivamente, no solo derrotada, sino además denigrada políticamente por sus vencedores. Pero el tratado de Versailles no tendría por qué entrometerse en las disquisiciones de un filósofo, pues no es la filosofía el terreno en el cual estas injusticias podían haber sido superadas. Y si bien las explicaciones psicológicas no son verdaderas explicaciones para los problemas que estamos tratando, no podemos negar que hay ciertos rasgos de carácter en Heidegger que lo han hecho proclive al discurso resentido y vengativo del nazismo. Por una parte, su proveniencia social, hijo de una familia humilde, obligado a abrirse paso en la vida en medio de grandes privaciones; por otra parte, hombre apegado al terruño, vestido como campesino para afirmar su pertenencia, sin mucho mundo, encerrado en su pequeño círculo académico y, con excepción de su interés por Grecia, sin ninguna apertura hacia las culturas de otros países o de otros hombres. Con grandes prejuicios sobre América y sobre Rusia. En el siglo de John Dos Passos, de Faulkner, de Hemingway, para él no existió la novela norteamericana, en el siglo del cine no se ocupa jamás de nada que tenga que ver con ello, en el siglo de Prokoviev, Stravinsky, Shostakovich no menciona jamás la música rusa; por otro lado, sus referentes pictóricos son limitadísimos (Van Gogh, Cézanne, Paul Klee, y algún otro), no menciona a Picasso o al surrealismo, que eran las principales fuerzas artísticas emergentes en su época.

En fin, ajeno a todo cosmopolitismo, se diría que para bien o para mal, en lo que atañe a ciertos prejuicios nacionales, su personalidad es enteramente provinciana y con respecto a eso valdrían perfectamente las ironías de Ortega y Gasset refiriéndose a Kierkegaard: "he ahí un ejemplo de laboratorio para quien quiera ver en qué consiste la enorme lacra que es el "provincianismo", cosa que es casi la inversa del buen provincialismo donde toda nación hunde sus raíces y de que se nutre. El provincial cree que su provincia es su provincia, pero el "provinciano cree que su provincia es el universo y su aldea una galaxia" (PL p. 372) Y más adelante afirma: "Muy especialmente es la filosofía lo contrario de todo provincianismo, porque consiste, quiera ella o no, en una perspectiva radical por su método y universalísima por su tema. Todas las demás perspectivas humanas son parciales y su "modo de pensar" o de sentir o de ser es un provincianismo del pensar, del sentir y del Ser. La filosofía siente repugnancia hacia cuanto es parte, parcialidad y partidismo. El filósofo nunca fue de un partido y todos quisieron adjudicárselo después" (PL p. 374). Lamentablemente esta deriva hacia el partidismo es lo que ha perdido a Heidegger y su única verdadera justificación es que felizmente esto ha durado solo algunos años de su vida.

La tercera característica atribuida a la modernidad se refiere a los aspectos más políticos y en ella se muestra del modo más claro la postura nacionalista. Como ya lo 
hemos visto, el nacionalismo filosófico de Heidegger consiste en pensar que Alemania se constituye como una alternativa frente a la modernidad; este aspecto tiene su correlato en lo político, pues la vocación alemana también se distinguiría de la experiencia histórica marcada por la emancipación individual propia de la Revolución Francesa. La experiencia de Alemania sería una en la cual la idea de libertad se habría modificado y, en cierto sentido, apartado de la del resto de los pueblos europeos, que han seguido un camino democrático. Esta libertad, en lugar de ser afirmación del individuo, sería una afirmación del espíritu de un pueblo dentro del cual el individuo es integrado. "Se despertó la conciencia de que fe y saber, lenguaje y arte, poesía y educación tienen sus raíces y medidas en el pueblo. Lo que determinaba la esencia del hombre era la esencia natural e histórica del espíritu de un pueblo (Volksgeist) y no las reglas de un mero entendimiento, ni los cálculos de una razón mundana que oscila libremente" (GA16 p. 291). Esta toma de posición nacionalista con respecto a Descartes es ya demostrativa de un desvío y comprende en sí la afirmación absurda de que Alemania estaría siguiendo su propio camino histórico, diferente del que han seguido las otras naciones europeas y en el cual el pueblo pasaría a ser protagonista histórico frente al individuo. El cartesianismo pondría el acento en la afirmación del individuo, de donde finalmente surgirían las consecuencias históricas de la revolución por la cual el protagonismo pasaría al ciudadano que afirma sus derechos individuales. Las libertades individuales no corresponderían a derechos humanos universales, sino que aparecerían de este modo como específicos de un tipo de pueblos, entre los cuales, por supuesto, no se cuenta a los alemanes. En la libertad específica de los alemanes no habría una oposición entre individuo y Estado, sino precisamente lo contrario, una unidad, y esta se expresaría nuevamente en el concepto de "obligación". "Libertad significa: obligación ligada de ese modo con la voluntad del Estado. Libertad es responsabilidad para con el destino de un pueblo" (GA16 p. 291).

Los chilenos que vivieron su exilio en Alemania contaban un chiste que pretendía resumir su pensamiento sobre los alemanes. Decían: "en Alemania, todo lo que no está prohibido, es obligatorio". Esto podría servir de ilustración a lo que Heidegger afirma, pues él pretende que el lazo fundamental que posee el ser humano con el Estado es el de una obligación. El ser humano libre sería paradójicamente el que se sometería a la voluntad del Estado. Esto lleva consigo además la exaltación del autoritarismo y de las relaciones jerárquicas que también han sido muchas veces mostradas como una característica de la sociedad alemana. Tal vez el ejemplo más significativo de esta singular tendencia ha sido mostrado por Primo Levi en el primer capítulo de su libro "La Tregua". Allí, en efecto, cuenta la historia de Thylle, un viejo alemán que gracias a su condición de prisionero político pudo sobrevivir a las terribles condiciones del campo de concentración. Cuando los soldados alemanes huyeron del campo por causa del rápido avance soviético, siendo él el único del campo que poseía esta condición de "político", fue rápidamente nombrado por los SS como "jefe del barracón del block 20" en el que también se encontraba Levi. En el relato de este episodio, Levi, sin ninguna ironía, y más que nada para explicar su conducta a partir de ese momento, dice: "Como era alemán se había tomado muy en serio aquel precario nombramiento". El pobre Thylle, alemán al fin y al cabo, a pesar de ser nombrado por sus 
propios enemigos que huían despavoridos ante el avance ruso, se sentía investido de un poder y una autoridad sobre sus compañeros y pretendía que su posición de jefe se hallaba así legitimada y la hacía respetar. Este tipo de relaciones autoritarias son por cierto bien alemanas y tienen que ver con una cultura tan asentada en el país, que el propio Heidegger ha sido víctima de ella. La idea de un orden autoritario como ideal de sociedad es profundamente chocante para un francés, un español o un italiano, pero el parecer constituye un ideal difícil de extirpar de la cabeza de un alemán.

La consecuencia más importante de esta idea es que, según Heidegger, ella sacaría a la luz una nueva concepción de la libertad, que significaría ahora "ligazón con la ley del espiritu de un pueblo... Libertad significa: obligación ligada de este modo con la voluntad del Estado. Libertad es responsabilidad para con el destino de un pueblo". La subordinación voluntaria del individuo al Estado, que efectivamente genera un tipo de sociabilidad extremadamente eficaz, representa en la realidad un tipo de maquinización de la sociedad que, ya lo hemos dicho, es la que se logra en los regimientos y en los ejércitos, pero que está lejos de ser útil para ampliar las posibilidades de expansión y creatividad del ser humano. Lo curioso es que esta maquinización militar es precisamente una manifestación flagrante de modernidad extrema y distorsionada y no una opción contrapuesta a ella, como nos la quiere mostrar Heidegger. Puede decirse entonces que lo que no ha comprendido el pensador alemán es que la historia no va por caminos separados y que la desviación que ha ido sufriendo Alemania en esos años se debe, más a una deformación o distorsión del camino histórico de Occidente, que a una verdadera opción nueva y diferente. Heidegger, como muchos otros alemanes en ese tiempo, ha creído ver en este tipo de organización una solución a los problemas políticos generados durante la República de Weimar, en la que efectivamente se desarticuló completamente la sociedad alemana. Esta desarticulación se le aparece como una tendencia general a la disgregación que atraviesa toda la sociedad, incluyendo la universidad. Lo que caracteriza la tendencia moderna es "El desligarse del hombre fuera de su comunidad y de las regulaciones ordinarias. El hombre que se sabe a sí mismo (algo) individual, es el elemento normativo y el fundamento configurador de la nueva regulación. La comunidad se hace ahora una sociedad, es decir, una asociación de muchos individuos en virtud de su compromiso y su contrato de acuerdo a una racionalidad. El Estado se halla fundado sobre un contrato" (GA16 p. 290).

La modernidad, al defender el valor de la individualidad y al basar todas sus consecuencias políticas en la autoafirmación de la conciencia, termina con la comunidad y genera su desarticulación. Por lo que Heidegger coincide con Hitler en su crítica a la democracia. En su explicación del proceso de decadencia de las universidades alemanas que, según él, el movimiento nacionalsocialista vendría a detener y superar, lo esencial es la oposición entre el proceso político que este movimiento lleva a cabo y lo que caracteriza el movimiento de modernidad característico de la Ilustración y la Revolución Francesa. Lo extraño es que también Heidegger interprete este fenómeno desde una perspectiva nacionalista, poniendo lo esencial del espíritu alemán en contraposición con este proceso. Mientras el liberalismo francés estará caracterizado por "el desligarse del hombre fuera de su comunidad y de las regulaciones ordinarias" 
-lo que engendraría la situación de desarraigo y de desarticulación característicos de las sociedades modernas- lo propio del espíritu alemán estaría dado por el sentido de unidad y de arraigo. Así, en la historia europea aparecerían enfrentadas dos opciones contrapuestas, una que conduce a la dispersión y al individualismo, y otra, representada por Alemania, que buscaría afirmar la pertenencia del individuo a su comunidad y consolidar una cultura unitaria, cuyo centro estaría dado por la filosofía y el pensamiento. Lo que marca más claramente esta diferencia sería la afirmación del "pueblo" entendido como una comunidad cultural (para Heidegger) y racial (para Hitler) frente a la sociedad, entendida como una comunidad de individuos libres e iguales, respondiendo a una normativa basada en la racionalidad. Alemania sería entonces un pueblo y no una sociedad como el resto de las naciones europeas.

En cuanto a la primera opción, Heidegger, como se ve, la explica como una derivación surgida sobre la base del pensamiento de Descartes: "El hombre que se sabe a sí mismo (esto es, el hombre determinado como conciencia desde la filosofía de Descartes) (algo) individual, es el elemento normativo y el fundamento configurador de una nueva regulación (GA16 p. 290). Al constituirse el Estado sobre un contrato, se han diluido las pertenencias de la situación anterior, en la cual los ciudadanos constituían una unidad a partir de sus lazos con la tierra, o como lo afirma el nazismo (y también Heidegger), con sus lazos de sangre y suelo (Blut und Boden). Así, la tendencia occidental hacia la democracia es vista como una disolución de estos lazos y como obligatoriedad abstracta basada en la razón. El cogito no solamente sería el fundamento del saber, sino además la base de la constitución de la sociedad, en la medida en que a partir de él aparece el hombre definido como individuo.

Por el contrario, en Alemania se habría producido una tendencia inversa, de reafirmación nacionalista que habría dado lugar a una concepción completamente diferente de la libertad: poetas, políticos y pensadores habrían creado un "mundo espiritual nuevo, en el que fueron comprendidos y pensados en su conjunto el predominio de la naturaleza y de los poderes de la historia unificados en la esencia del absoluto". Lo esencial estaría dado por una nueva idea del hombre, diferente al individuo consciente cartesiano y en la cual lo fundamental estará en el "espíritu del pueblo", y consiguientemente por el sentido de lo popular y lo comunitario. Esta idea aplicada a la conformación del Estado da lugar a una reforma en la cual este aparece como "una ordenación vital y una ley en la cual y por la cual el pueblo mismo conquista su unidad y la seguridad de su duración" (GA16 p. 291). Así se habría modificado completamente la relación del hombre con su Estado y su experiencia de la libertad definida, reiteramos, como obligación: "Libertad significa: obligación ligada de ese modo con la voluntad del Estado" (GA16 p. 291). Todas estas ideas corresponden a lo que con posterioridad a la segunda guerra algunos han llamado "la revolución conservadora" y que además de estas ideas de Heidegger incluye las de Jünger y de Karl Schmitt. Ellas explican el viso favorable que tuvo en un momento para estos pensadores el nacionalsocialismo, aunque el grado de compromiso que los tres han tenido con el nazismo haya sido en cada caso diferente. En el caso de Heidegger, la idea de "pueblo", tal como se afirma en diversos documentos aclaratorios de su compromiso con el hitlerismo, tiene más que nada una connotación cultural, por lo que no debiera ser 
asimilada al nazismo puro y duro, para el cual el "pueblo" se constituye fundamentalmente a partir de la raza. Ejemplo de este tipo de aclaraciones es la frase "Solo un mundo espiritual garantiza a un pueblo la grandeza" que encontramos en su Discurso de Rectorado (SDU, pp. 12-13) y que el propio Heidegger cita en su "Carta al rectorado académico" (EP, p. 197) como prueba de su distanciamiento del biologismo nazi.

En su enumeración de los filósofos alemanes que habrían contribuido a dar nacimiento a las nuevas ideas de las relaciones entre Estado y libertad, Heidegger sospechosamente olvida a Nietzsche, quien, si seguimos su interpretación nacionalista, debería figurar como un filósofo "francés". En efecto, pocos pensadores han sido tan radicales como Nietzsche en su denuncia de los peligros que conlleva el Estado, definido en Así habló Zaratustra como "el más frío de los monstruos fríos". La identificación propia del nacionalsocialismo entre las nociones de pueblo y Estado, que Heidegger repite acríticamente en su conferencia, están ya denunciadas en forma clara por Nietzsche en su poema: "Donde aún hay pueblo, éste no comprende al estado y lo odia como un mal de ojo y un pecado contra las costumbres y los derechos". "Estado llamo yo al lugar donde están todos los bebedores de venenos, ya sean buenos o malos: estado, donde todos se pierden a si mismos, ya sean buenos o malos: estado, donde el lento suicidio de todos - se llama "la vida" (WdW p. 313). Y esto es un importante indicador de que la propia historia de la filosofía alemana está interpretada por Heidegger en una dirección forzadamente nacionalista que nada tiene que ver con la realidad. La influencia de la Revolución Francesa en Alemania fue mucho mayor de lo que él querría reconocer y no hay ningún filósofo del idealismo alemán que no haya recibido su influjo. Las Consideraciones destinadas a rectificar los juicios del público sobre la Revolución Francesa de Fichte son un buen ejemplo de esto, que ciertamente no necesitaría de ningún ejemplo, pues es una verdad que salta a la vista de cualquier lector que no tenga nublada la visión con criterios nacionalistas. Heidegger busca mostrar la originalidad de los alemanes frente a los pensadores del resto de Europa, sin asumir que dicha originalidad solo puede mostrarse como prolongación o expansión de lo que es el camino común del pensamiento europeo occidental. La obra de Nietzsche está llena de referencias al espíritu europeo y de críticas al nacionalismo alemán. Además de esto, Humano, demasiado humano está dedicada a Voltaire, "uno de los grandes liberadores del espíritu" y tiene como Prefacio una cita de Descartes. Por lo tanto, lo característico alemán que Heidegger pretende descubrir no es más que una selección suya de ciertas tendencias que por supuesto también han existido, pero que ni siquiera son las preponderantes o las más significativas de la historia del pensamiento político de su país.

Para el Heidegger de comienzos de los años treinta, lo positivo del nazismo radicaría en que este sería un contra-movimiento frente a la modernidad racionalista y técnica, el cual, frente al estado de disolución promovido por la democracia parlamentaria intentaría reconstruir la nación a partir del concepto de "pueblo", superando así la idea de "sociedad" de individuos libres e iguales surgida a partir de la Revolución Francesa. Como el movimiento técnico desarraiga al ser humano de sus pertenencias, transformándolo en una entidad abstracta - el individuo ajeno a su facticidad, desprovisto de sus particularidades- Heidegger pretende que el nazismo podría ser 
una respuesta adecuada a este problema, y en cuanto su exagerado antisemitismo, podría ser un exceso corregible, lo importante de él sería su tendencia a afirmar lo constitutivo del pueblo, su esencial arraigo, sus lazos con la tierra y la sangre. Esta idea del arraigo también tiene una evolución en su pensamiento, que en un primer momento es relativamente indiferente a los excesos racistas, aunque no los comparta enteramente, para posteriormente presentarse como una vuelta a la tierra poética y cultural. Por este motivo, la crítica a la democracia no termina con su alejamiento del nazismo. Todavía en la entrevista a Der Spiegel de 1966 esta es mantenida en los siguientes términos: "Es para mí hoy día una cuestión decisiva saber cómo se puede hacer corresponder en general un sistema político con la era técnica y qué sistema podría ser. No sé responder a esta cuestión. No estoy persuadido de que sea la democracia".

Por otro lado, es interesante comparar esta interpretación positiva del nazismo con la interpretación crítica que ha hecho Levinas en su ensayo sobre la filosofía del Hitlerismo $(\mathrm{PhH})$, el cual, si bien cae en la exageración de tomar el hitlerismo como una "filosofía", vale como el primer intento verdaderamente filosófico de interpretación de este fenómeno. En su pequeño pero determinante opúsculo escrito en 1934, él parte también estableciendo una tendencia histórica dicotómica en el pensamiento occidental, caracterizado en su línea fundamental, tanto judaica como griega, a partir de la separación entre razón y cuerpo, es decir, por la posibilidad de afirmarse la razón por encima del cuerpo y sus determinaciones. El nazismo, en cambio, significaría un contramovimiento a esta tendencia, que buscaría mostrar al hombre en su ser arraigado al cuerpo (raza), identificado en forma rígida con él e incluso definido por esta identificación. La expresión utilizada por Levinas es el être rivé, el ser enclavado en su circunstancia física y material, incluso biológica, lo que se opondría a la afirmación de una libertad absoluta, cuya vocación suprema sería distanciarse constantemente de lo material. Con ello, el hitlerismo llevaría dentro de sí la negación de la historia y la reducción del hombre a su pura animalidad. El nazismo no solamente sería un atentado en contra de la democracia, del parlamentarismo, del liberalismo y del cristianismo, sino en contra de la esencia misma del hombre.

Giorgio Agamben, en una conferencia sobre Heidegger y el nazismo (PP) pone acertadamente esta interpretación de Levinas en relación con la idea de facticidad de Heidegger expuesta en Ser y tiempo, con lo cual se hace posible en este sentido establecer un vínculo entre su filosofía y dicho movimiento político. La insistencia de Heidegger en el arraigo, tendría su fundamento en la facticidad, entendida como la condición de caída de la existencia, frente a la cual ningún poder es capaz de actuar. El hombre es irremisiblemente lo que en cada momento su circunstancia factual configura. La insistencia de Heidegger en este "ser caído" sería el vínculo que su filosofía podría tener con el hitlerismo, en cuanto la esencia de este radicaría en la anulación de la libertad y en la afirmación de los determinantes biológicos de la existencia humana. 
En realidad, esta interpretación del pensamiento de Heidegger es unilateral, pues lo que a nuestro parecer busca el pensador alemán es establecer como esencia humana la facticidad y la libertad al mismo tiempo, y en ningún caso una de estas realidades separada de la otra. Así es como para pensar adecuadamente este punto se hace necesario afirmar conjuntamente lo destinal de la facticidad con lo libertario de la existencia. Sartre comprendió estas relaciones de manera adecuada y las expresó muy claramente en los conceptos de "facticidad" y "trascendencia", a pesar de que, empujado por un cierto racionalismo, no llegó a desligarse completamente de las exigencias lógicas de un pensamiento lineal. En todo caso, su propia explicación de la mala fe muestra muy nítidamente el modo como pueden malentenderse estas relaciones cuando se cae en la unilateralidad. De acuerdo con su descripción, la mala fe se produce cuando la trascendencia se presenta como facticidad o, al revés, cuando la facticidad se muestra como trascendencia. Para no enredarnos en estas definiciones, digamos que hay tres formas de presentarse las relaciones entre facticidad y trascendencia: la primera de ellas es cuando se afirman ambas al mismo tiempo, que es a mi parecer lo que ha intentado llevar a cabo Heidegger en Ser y tiempo. La segunda y la tercera posibilidad corresponden a lo que Sartre llama "la mala fe", y consisten en presentar la trascendencia como facticidad o, al revés, la facticidad como trascendencia.

Veamos esto en el ejemplo que pone el mismo Sartre en El ser y la nada. Para explicarse pone dos ejemplos: el título de una obra de Jacques Chardonne "El amor es mucho más que el amor", expresión con la que se afirma de hecho de que el amor fáctico (sensualidad, contacto de dos epidermis, lucha adleriana de los sexos, etc.) es más que eso que, presentado de este modo, pareciera despreciable, sublimándoselo hacia lo trascendente (al amor platónico, poético, cósmico. etc.). Así, la aparente afirmación del amor en el primer sentido es en realidad una negación de él, con el objeto de hacer aparecer la importancia de su opuesto. Bajo el pretexto de una definición de lo fáctico, se lo niega para afirmar lo trascendente. Así, lo que aparentemente se afirma, resulta negado y lo que aparentemente se niega, resulta afirmado. El segundo ejemplo es el título de una obra de teatro de Sarment "Yo soy demasiado grande para mí mismo", con lo cual se afirma y se niega a la vez lo que yo soy, o, mejor todavía, se niega lo que sin duda soy, aunque no me guste serlo, para afirmar lo que no soy o que soy, pero sin dejar de ser lo que no me gustaría ser. Lo que aparece en un primer momento como modestia es, en realidad, soberbia, esto es, una manera embozada de afirmar mi propia grandeza. De ese modo, la mala fe aparece como una modalidad de conducta interesante desde el punto de vista metafísico, pues su estructura de ser es siempre la afirmación de que soy lo que no soy, o de que no soy lo que soy. Esta duplicidad, sin embargo, es de distinta naturaleza que la definición que se podría dar de la propia existencia (el "para sí"), la cual, por no ser nada predefinido de antemano y por estar necesariamente entregada a la determinación libre del individuo que la sostiene, también puede definirse como un modo de ser y no ser al mismo tiempo, o de no ser lo que se es y de ser lo que no se es. La diferencia entre esta última formulación y la mala fe está en que la primera, para dar cuenta de lo pensado en esa fórmula, exige que ambas instancias, la facticidad y la trascendencia, se afirmen cada vez simultáneamente, sin poder separarlas ni en favor de una ni en favor de la otra. Por el contrario, cuando la 
misma estructura da lugar a la mala fe, la negación o la afirmación se separan de su contrario y se afirman por separado, de manera unilateral. Así, la frase "yo soy lo que no soy" cuando es de mala fe, significa en verdad una afirmación de lo que no soy y, por tanto, una falsificación de mi propio ser y una caída de lleno en la inautenticidad. Lo mismo vale en el caso contrario. En realidad, la mala fe es una artimaña para afirmar lo que soy o lo que no soy, a través de la expresión de lo contrario y no un modo de afirmar conjuntamente ambas cosas, que es lo que caracteriza a la existencia. De ahí que para caracterizar correctamente a esta última estoy siempre obligado a afirmar ambas cosas en un sentido y en otro: yo soy lo que no soy y yo no soy lo que soy. En el caso de la mala fe, en cambio, siempre hay, o bien una afirmación, o bien una negación, pero no ambas a la vez.

Ahora bien, lo que ha acontecido con el hitlerismo, y también con Heidegger, a pesar de su lucidez en su punto de partida, es que la facticidad se ha afirmado bajo esta modalidad de la mala fe. Cuando se dice que yo soy mi raza, que me defino por ella, o que yo soy lo que define mi arraigo, en realidad estoy diciendo que mi ser, que en principio es también contingente y libre, por tanto ligado y desligado de mi circunstancia, se define por ella, se enclaustra en ella, apareciendo falsamente como una facticidad no contingente, sino que necesaria. "Yo soy mi raza" significa que en relación con mi raza yo pierdo mi libertad, dejo de ser contingente, pero como el hombre no puede ser jamás una facticidad puramente fáctica, esta afirmación niega en realidad lo que de hecho afirma, o afirma en los hechos lo que ella misma niega.

Aplicado esto a la interpretación de la relación entre el nazismo y el pensamiento de Heidegger, tendríamos que concluir que si es detectable en él un nazismo de cualquier tipo, ello solo ha sido posible porque el pensador no ha sabido ser consecuente con su propio pensamiento y en lugar de afirmar consecuentemente una facticidad situada, pero al mismo tiempo libre, ha tendido en algunos momentos de su vida a huir de la libertad para protegerse en su facticidad. Hay mala fe en sus posiciones nacionalistas, puesto que todo nacionalismo, no solamente el del nacionalsocialismo, constituye una afirmación de mala fe, en cuanto transforma en pura facticidad algo que también es y siempre, a la vez, pura contingencia o pura trascendencia. Y en este punto, para ser enteramente justos, tenemos que afirmar que a pesar de ser Heidegger el primero en pensar al hombre en su unidad de libertad y destino, ha sido Sartre quien ha buscado a lo largo de toda su vida una mayor consecuencia en este aspecto y en más de un momento lo ha logrado. Al revés, la preocupación por la facticidad y la búsqueda del arraigo en Heidegger se han constituido finalmente en una trampa, de la que a pesar de su grandeza de pensamiento, por debilidades personales, él no ha podido librarse. Tal vez sea por eso que ha sido Sartre quien de mejor manera ha sabido situarse frente al nazismo de Heidegger, tal como lo muestra su intervención "A propos de l'existentialisme: mise au point" en la revista Action del 29 de diciembre de 1944, en la primera polémica sobre este hecho que tuvo lugar en Francia y en la que afirma: "Heidegger era filósofo mucho antes de ser nazi. Su adhesión al hitlerismo se expresa por el miedo, el arribismo tal vez, seguramente el conformismo: no es hermoso, lo admito. Sólo que eso basta para invalidar vuestro hermoso razonamiento: "Heidegger"-decís- "es miembro del partido nacional-socialista, por 
lo tanto su filosofía debe ser nazi”. No es eso: Heidegger no tiene carácter, ésa es la verdad. ¿Os atreveréis a concluir de ello que su filosofía es una apología de la cobardia? ¿No sabéis que a los hombres les sucede no estar a la altura de sus obras?"

Referencias bibliográficas y abreviaturas

GA16: Heidegger Martin (2000), Gesamtausgabe, I Abteilung: Veröffentlichte Schriften 1910-1076, Band 16, Reden und andere Zeugnisse eines Lebensweges. Frankfurt am Main: Vittorio Klostermann $\mathrm{GmbH}^{1}$.

GA50: Heidegger Martin (1990), Gesamtausgabe, II. Abteilung: Vorlesungen 19191944, Band 50 1. Nietzsches Metaphysik 2. Einleitung in die Philosophie. Denken und Dichten. Frankfurt am Main: Vittorio Klostermann GmbH.

EP: Heidegger Martin (1995), Écrits Politiques 1933-1966. Présentation, traduction et notes par François Fédier. Paris: Editions Gallimard.

CMO: Losurdo Domenico (1991), La comunità, la morte, l'Occidente: Heidegger e l'ideologia Della guerra. Torino: Bollati Boringhieri.

IA: $\quad$ M. Heidegger (1952), Einführung in die Metaphysik. Max Niemayer.

SDU: Heidegger Martin (1982), Die Selbsbehauptung der deutschen Universität. Trans-Europ-Repress, Francia.

LD: $\quad$ Kart Löwith (1986), Mein Leben in Deutschland vor und nach 1933. Ein Bericht. J.B. Stuttgart: Metzlersche Verlagsbuchhandlung und Carl Ernst Poeschel Verlag GmbH.

WdW: Nietzsche Friedrich (1955), Werke in drei Bänden. Herausgegeben von Karl Schlechta, Zweiter Band. München: Carl Hansen Verlag.

PhA: Ernst Cassirer (1932), Philosophie der Aufklärung. New Haven: Yale University Press.

PL: J. Ortega y Gasset (1958), La idea de principio en Leibniz. Buenos Aires: EMECÉ Editores.

PhH: Emmanuel Levinas (1997), Quelques réflexions sur la philosophie de l'hitlerisme. Paris: Éditions Payot \& Rivages.

PP: $\quad$ Giogio Agamben (2007), La potencia del pensamiento (traducción de Flavio Costa y Edgardo Castro). Córdoba, Argentina: Adriana Hidalgo Editora.

Para las citas del texto "Die deutsche Universität" incluido en este libro hemos utilizado la versión en español de Breno Onetto publicada en la página www.heideggeriana.com.ar por el filósofo argentino Horacio Potel. 